\title{
Characterization of somatic antigens of adult Toxocara canis by western blotting
}

\author{
Shivani Sahu' ${ }^{1}$, S. Samanta ${ }^{1}$, N. R. Sudhakar ${ }^{1}$, O. K. Raina ${ }^{1}$, S.C. Gupta ${ }^{1}$, T.K. Goswami ${ }^{2}$, \\ D. N. Madhu', and Ashok Kumar ${ }^{4}$
}

1. Division of Parasitology, Indian Veterinary Research Institute, Izatnagar 243122, UP, India;

2. Immunology Section, Indian Veterinary Research Institute, Izatnagar 243122, UP, India; 3. Division of Surgery, Indian Veterinary Research Institute, Izatnagar 243122.4, UP, India; Division of Veterinary Public Health, Indian Veterinary Research Institute, Izatnagar. 243122, UP, India.

Corresponding author: N. R. Sudhakar, email:sudhi463@gmail.com

Received: 22-11-2012, Accepted: 29-12-2012, Published online: 26-04-2013

\section{How to cite this article:}

Sahu S, Samanta S, Sudhakar NR, Raina OK, Gupta SC, Goswami TK, Madhu DN and Kumar A (2013) Characterization of somatic antigens of adult Toxocara canis by western blotting, Vet World 6(7): 424-427, doi: 10.5455/vetworld.2013.424-427

\begin{abstract}
Aim: The objective of this study was characterize the somatic soluble antigens of adult Toxocara canis (Tc-SA) by western blotting.

Materials and Methods: T. canis worms were collected from the naturally infected pups after deworming. The somatic antigen was prepared as per standard procedure with slight modification. These antigens were separated using Sodium dodecyl sulphate-electrophoresis (SDS-PAGE). The specific reactivity of the Tc-SA proteins was checked against the serum of naturally infected dogs as well with the hyperimmune serum raised in the rabbit by western blotting.

Results: On SDS-PAGE recovered proteins ranged in size from 44 to $300 \mathrm{kDa}$. The immuno-reactivity of the naturally infected dog sera with the Tc-SA antigens showed 12 prominent immunoreactive bands of distinct sizes at 28.61, 32.60, 38.10, $43.04,49.99,67.57,73.22,105.77,144.74,161.11,177.84$ and $196.31 \mathrm{kDa}$. The immuno-reactivity of the hyper immune serum raised in rabbits against Tc-SA antigens was observed with 10 prominent bands of distinct sizes at 17.11, 24.15, 34.83, 43.46, 52.47, 55.89, 67.57, 70, 74.60 and $105.6 \mathrm{kDa}$.
\end{abstract}

Conclusions: Common antigens band were observed at 67 and $105 \mathrm{kDa}$. These antigens merit further evaluation as candidate for use in diagnosis of toxocarosis in humans and adult dogs.

Keywords: diagnosis, Somatic-antigens, Toxocara canis, western blotting

\section{Introduction}

Toxocara canis is a wide spread gastrointestinal nematode of dogs and other canids and is the causative agent of zoonotic disease in humans [1]. Larval stages of $T$. canis parasite have an obligatory tissue-migratory phase, giving rise to a drug resistant reservoir in dogs, and visceral larva migrans in humans [2,3].

Human infection is present worldwide and is a consequence of the habit of keeping dogs and cats for company, which favours the persistence of the parasite in the environment and its transmission [4]. In India, studies on the prevalence of human toxocarosis is very scarce and reports shows that its prevalence is $32.86 \%$ in Kashmir valley and $6.4 \%$ in subjects residing in a rural area near Chandigarh [5]. In the other developing countries, this scenario is probably worse, Children playing in areas contaminated with dog faeces, as well as people with intimate contact with dogs, are subject to a higher risk of infection [6]. In the Developed countries like United States, human toxocarosis is the most common human parasitic worm infection and affects $13.9 \%$ of the population [7].

This article is an open access article licensed under the terms of the Creative Commons Attribution License (http://creativecommons org/licenses/by/2.0) which permits unrestricted use, distribution and reproduction in any medium, provided the work is properly cited.
The cross-reactivity with antibodies from other endemic helminth infections is a limitation for the development of an accurate serodiagnostic test [Enzyme Linked Immunosorbent Assay (ELISA)] using the unfractionated excretory-secretory (ES) antigens from the $T$. canis second-stage larvae (TES Ag) [8]. In recent years, there have been important methodolo-gical advances in the diagnosis of many infectious diseases, but there are innumerable difficulties in the laboratory diagnosis of toxocarosis due to the laborious production of the antigens or the high costs of commercial diagnostic kits [9].

In the absence of parasitological evidence of infection, immunological methods are required for its diagnosis. The diagnosis of human toxocarosis depends on clinical and serological data because detecting Toxocara larvae by biopsy is difficult [10]. Since the development of the ELISA using ES antigens from TES Ag described by de Savigny et al. [11] and the subsequent western-blot method using the same antigen by Magnaval et al.[12], a general agreement has existed regarding the value of the TES Ag for the immunodiagnosis of human toxocarosis.

Recently number of diagnostic candidates have been investigated like Toxocara excretory-secretory antigen (TES-57) and recombinant Toxocara 
excretory-secretory antigens (rTES-120, rTES-26, rTES-30USM) [13]. Presently a Dot-ELISA test for toxocarosis is under evaluation which is considered as a reliable one as it presents many advantages as a basic diagnostic test. For example, it is highly stable, it does not require specialised tools to analyse the results, it has a lower cost and it can be simultaneously applied to a large number of samples by a basically trained technical staff $[14,15]$.

There are molecular weight moieties observed in adult worms that may be related to the larval TC-ES products [16]. The parasite proteins of this antigen which ellicit an immune response can be identified by immunological techniques. Therefore, this paper includes the identification and characterization of the antigenic components of adult $T$. canis present in the somatic soluble product using the western blot technique.

\section{Materials and Methods}

Parasite: Three pups of age group between 1-6 months were screened at random. They were examined for the natural infection of $T$. canis by faecal examination. The adult $T$. canis worms were then collected from the positive pups after deworming with a dose of piperazine citrate @ 220mg/kg of body weight. The expelled worms were identified, washed three times with $0.9 \% \mathrm{NaCl}$ and frozen in $70 \%$ ethanol at $-40^{\circ} \mathrm{C}$ until further use.

Adult somatic antigens: The somatic antigen was prepared as per the Peixoto et al., with slight modification [17]. Whole somatic antigens were prepared by homogenization of adult worms in presence of cocktail of protease inhibitors, thereafter subjected for sonication at 8-10 micron peak to peak for 15 cycles with an interval of $30 \mathrm{sec}$. every time strictly maintaining the cold chain. The sonicated material was then centrifuged at $15000 \mathrm{rpm}$ for $40 \mathrm{~min}$ at $4^{\circ} \mathrm{C}$. The supernatant was collected thereafter and designated as soluble protein fraction of $T$. canis somatic antigen (TcSA) and kept in aliquots at $-20^{\circ} \mathrm{C}$ for further experiment. Protein concentration was determined as the method of Lowry et al., [18].

SDS-PAGE analysis: The SDS-PAGE was carried out as per the method of Laemmli (1970) for characterization of somatic soluble proteins. [19].

Raising of hyper immune serum against TC-SA antigen: Two New Zealand White rabbits, weighing approximately $1.5 \mathrm{~kg}$ each, were injected with Tc-SA at the dose rate of $300 \mu \mathrm{g}$ per animal deep I/M. Somatic soluble antigen of adult $T$. canis was emulsified in equal volume of Freund's complete adjuvant (FCA) and used for primary immunization. Two successive booster doses were given along with Freund's incomplete adjuvant, 15days apart. Rabbits were bled after 10 days of the $1^{\text {st }}$ and $2^{\text {nd }}$ booster and the serum was collected and stored at $-20^{\circ} \mathrm{C}$ for further use.

Enzyme Linked Immunosorbent Assay (ELISA): Indirect ELISA was performed for detection of antibody response in rabbits experimentally immunized with TcSA antigen as per Wijfells et al. [20]. The intensity of colour reaction was measured as absorbance in each well at 492nm in an ELISA reader.

Western blotting: Western blotting was done to recognize the immunodominant polypeptides of Tc-SA antigen using standard procedure of Burnette [21] with slight modifications. The resolved proteins were subsequently transferred to a Nitrocellulose (NC) membrane. Blotting was carried out in ATTO semi dry blot transfer machine, AE6670 (ATTO Corporation, Japan)[21].

Development of blot: The NC paper was recovered after electrophoretic transfer and each lane was cut into strips. Successful transfer of the protein to the membrane was confirmed by staining the membrane with Ponceau's stain. Later, the strips were incubated with naturally infected dog sera diluted in PBS-T and the hyper immune sera raised against TC-SA antigen in rabbit diluted in PBS-T. Finally, they were incubated with goat anti-rabbit IgG-HRP and lately with rabbit anti-dog IgG-HRP, followed by development of blot using diaminobenzidine colour reagent system.

\section{Results}

SDS-PAGE analysis: On SDS-PAGE analysis, Tc-SA antigen revealed 14 protein bands ranging in size from 44 to $300 \mathrm{kDa}$, with a molecular moieties of 300 , 182.17, 144.24, 105.31, 96.56, 93.97, 91.04, 83.34, 81.11, 79.47, 75.95, 71.45, 67.97 and $44 \mathrm{kDa}$ (Fig-1).

ELI SA: Indirect ELISA was performed with two rabbits hyperimmunised with Tc-SA antigens and a high titre of IgG immunoglobulin response of 1: 50,000 was observed (Fig-2).

Western blotting: The specific reactivity of the Tc-SA was checked by western blotting. The immunoreactivity of the naturally infected dog sera with the TcSA antigens showed 12 bands at 28.61, 32.60, 38.10, 43.04, 49.99, 67.57, 73.22, 105.77, 144.74, 161.11, 177.84 and $196.31 \mathrm{kDa}$ (Fig-3). The immuno-reactivity of the hyper immune serum raised in rabbits against TcSA antigens was observed with 10 polypeptides at $17.11,24.15,34.83,43.46,52.47,55.89,67.57,70$, 74.60 and $105.6 \mathrm{kDa}$ (Fig-4).

\section{Discussion}

Protein bands of adult $T$. canis worm recovered in this study appear similar in molecular weight to those associated with adult $T$. canis proteins reported by ElMassry [22] at 91.04 (90), 67.97 (69.25) and $44 \mathrm{kDa}$ (46.57-47.13 kDa) [22]. Sun et al. 2007 described the SDS-PAGE protein profile of adult $T$. canis ranging in size from 3.4 to $325 \mathrm{kDa}$ [23]. Protein bands of adult $T$. canis viz. 91.04, 67.97 and $44 \mathrm{kDa}$ in the present study can be compared to those reported in the study of Sun et al., like 92.8, 69.4 and 48.4 kDa [23]. Nawal and Mona [24] reported the electrophoretic analysis of Tc-SA 


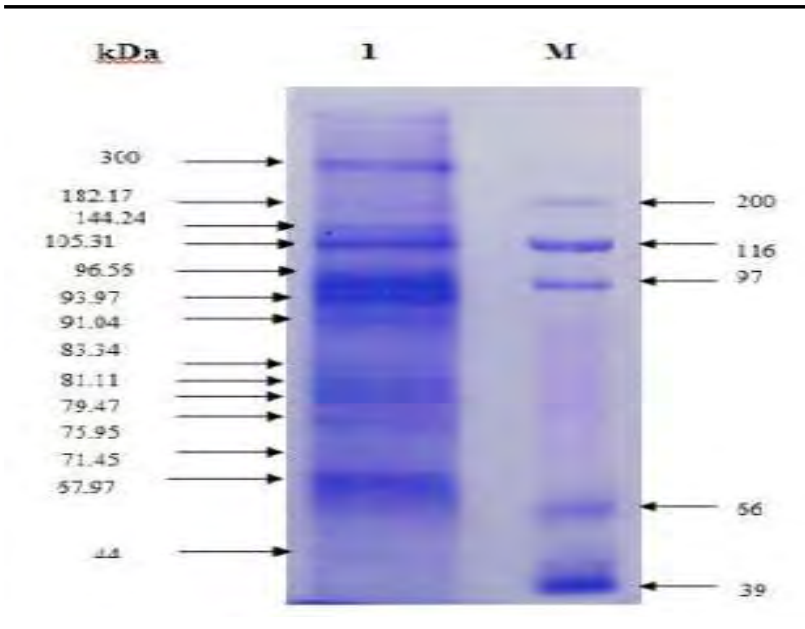

Fig-1. SDS-PAGE analysis of somatic antigens of adult T. canis Lane $\mathrm{M}$ : Protein molecular weight marker Lane 1: Somatic antigens of adult $T$. canis

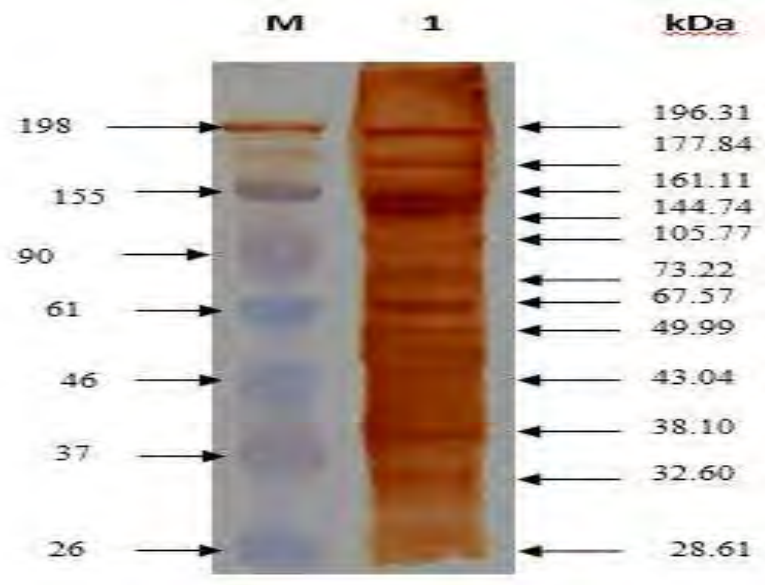

Fig-3. Western blotting showing immuno-dominant polypeptides reactive to $\mathrm{T}$. canis infected dog serum Lane $\mathrm{M}$ : Protein molecular weight marker Lane 1: Somatic antigens of adult T. canis

which revealed 13 polypeptide bands at $250,125,117$, $90.43,69.25,56.76,42.50,40.69,38,35.70,27.91$, 21.98 and $19.29 \mathrm{kDa}$. Aida, [25] reported the SDSPAGE profile of adult Tc-SA consisting of 7 (125.37, $117.73,90.00,69.25,58.36,47.13$ and $46.53 \mathrm{kDa})$ protein bands.

Peixoto and co-workers [17] identified specific antigens from the adult stages of $T$. canis including 42 , 58,68 and $97 \mathrm{kDa}$ that may be useful for the serodiagnosis of human toxocarosis. These antigens demonstrated considerable sensitivity and specificity and were considered as promising candidates for immunodiagnosis. The combination of the 58 and 68 $\mathrm{kDa}$ antigens was specific and sensitive for the antiToxocara antibody, supporting the possibility of using these two antigens for the immunodiagnosis of human toxocarosis in low-prevalent areas [17]. Further there are also reports that there is close taxonomic relationship between Ascaris sp. and Toxocara sp., and serological diagnosis there may be cross reactions as the two ascarids undoubtedly share antigens and epitopes [26].

We did a preliminary evaluation on the usefulness of soluble somatic antigens of adult T.canis as potential immunodiagnostic antigens. Compared to juveniles,

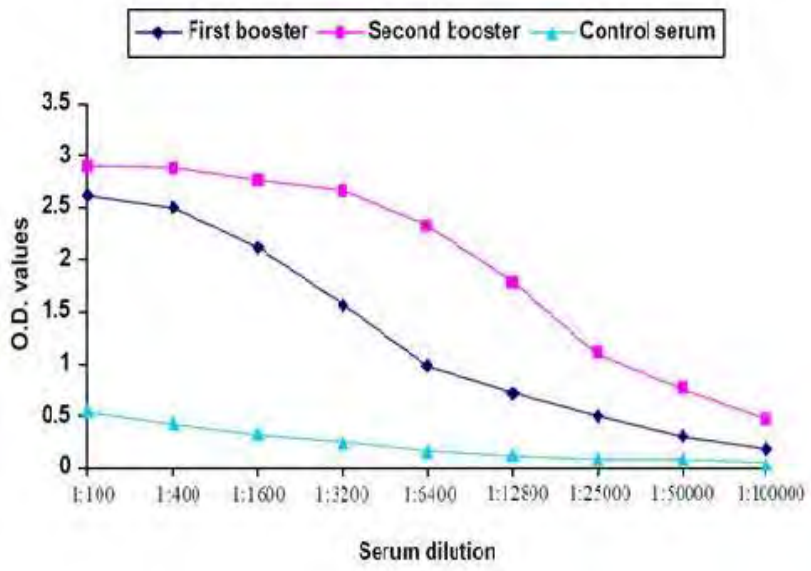

Fig-2. ELISA showing reciprocal serum dilution of rabbit, hyperimmunized with $\mathrm{T}$. canis somatic antigens

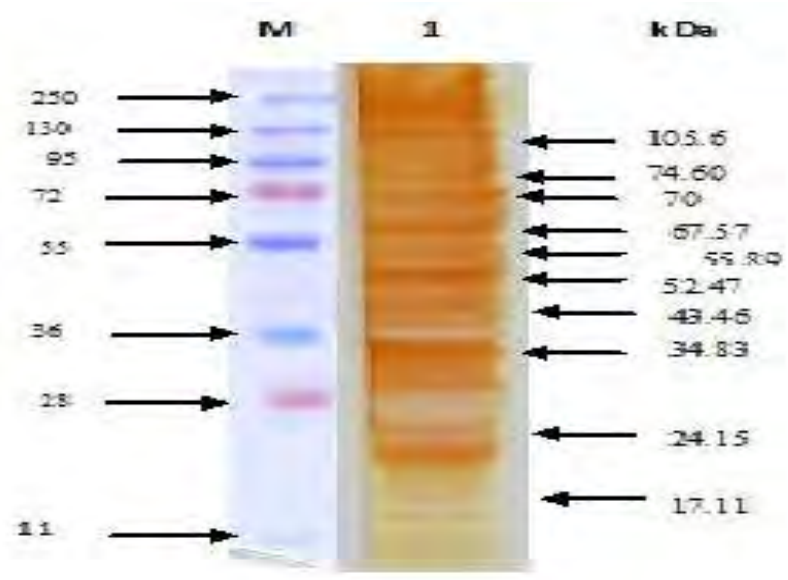

Fig-4. Western blotting showing immuno-dominant polypeptides reactive to hyper immune sera raised in rabbit against $T$. canis somatic antigens Lane M: Protein molecular weight marker Lane 1: Somatic antigens of adult $T$. canis

adult worms may be a better source of antigens because they are relatively easier to obtain and handle. The immunoreactivity of the anti-sera raised against Tc-SA in rabbit was observed at $17.11,24.15,34.83,43.46$, $52.47,55.89,67.57,70,74.60$ and $105.6 \mathrm{kDa}$ and the immunoreactivity with the naturally infected dog sera was observed at approximately $28.61,32.60,38.10$, 43.04, 49.99, 67.57, 73.22, 105.77, 144.74, 161.11, 177.84 and $196.31 \mathrm{kDa}$. We observed common immune dominant band at 67 and $105 \mathrm{kDa}$ with both of hyperimmune and dog sera. These antigens merit further evaluation as candidate for use in diagnosis of toxocarosis in humans and adult dogs. However, detailed studies are required for characterizing the immuno-dominant polypeptides of the adult worm for their potential in the diagnosis of toxocarosis in dogs and in humans.

\section{Conclusion}

In the present study, we identified and characterized the somatic soluble antigens of Toxocara canis adult worm. We observed two common immunodominant bands at 67 and $105 \mathrm{kDa}$. Further tests need to be performed to test whether these semi-purified adult Toxocara antigens might cross-react with other parasitic 
infections, mainly those caused by nematodes, to further confirm the specificity of such antigens. Moreover the efficacy of the adult worm antigens should be tested to know whether these antigens are similar to the larval ES antigen, which is currently used as a standard diagnostic reagent. At last production of recombinant version of these antigens is needed which will not only standardize the routine diagnoses, but also allow the determination of the epidemiology of toxocarosis in humans and adult dogs through seroprevalence surveys.

\section{Authors' contribution}

SS designed the study, analysed and interpreted data, drafted the manuscript. SNR, SS and MDN collected, identified parasites and drafted manuscript. TKG helped in using his lab to carry out the work and he is also personally involved in carrying out the study. OKR, SCG and AK revised the manuscript. All authors read and approved the final manuscript.

\section{Acknowledgements}

The authors are thankful to the Director, I.V.R.I, Izatnagar for providing necessary facilities to carry out the research work and ICAR funded outreach project on zoonotic diseases, India. Letter number. F. 14(1)/2009-ASR-IV $28^{\text {th }}$ August 2009.

\section{Competing interest}

Authors declare that they have no competing interest.

\section{References}

1. Despommier, D. (2003) "Toxocariasis: clinical aspects, epidemiology, medical ecology, and molecular aspects". Clin Microbiol Rev, 16 (2): 265-272.

2. Vidal, J.E., Sztajnbok, J. and Seguro, A.C. (2003) Eosinophilic meningoencephalitis due to Toxocara canis: case report and review of literature. American Journal of Tropical Medicine and Hygiene, 69:341-343.

3. Hotez, P.J, Wilkins, P.P. (2009) Toxocariasis: America's most common neglected infection of poverty and a helminthiasis of global importance? PLoS Negl Trop Dis 3(3):e400.

4. Delgado, O. And Rodriguez-Morales, A.J. (2009) Aspectos clínico-epidemiológicos de la toxocariasis: una enfermedad desatendida en Venezuela y América Latina. Bol Mal Salud $A m b, 1: 1-33$.

5. Malla, N., Aggarwal, A.K. and Mahajan, R.C. (2002) A serological study of human toxocariasis in north India. The National Medical Journal of India, 15(3):145-47.

6. Espinoza, Y.A., Huapaya, P.H., Roldán, W.H., Jiménez, S., Arce, Z. And Lopez, E. (2008) Clinical and serological evidence of Toxocara infection in school children from Morrope district, Lambayeque, Peru. Rev Inst Med Trop Sao Paulo, 50: 101-105.

7. Jones, J.L., Kruszon-Moran, D., Won, K., Wilson, M. And Schantz, P.M. (2008) Toxoplasma gondii and Toxocara spp co-infection. Am J Trop Med Hyg, 78: 35-39.

8. Smith, H., Holland, C., Taylor, M., Magnaval, J.F, Schantz, P. and Maizels, R. (2009) How common is human toxocariasis? Towards standardizing our knowledge. Trends Parasitol, 25: 182-188.

9. Colli, C., Rubinsky-Elefant, G., Paludo, M., Falavigna, D., Guilherme, E. and Mattia, S. (2010) Serological, clinical and epidemiological evaluation of toxocariasis in urban areas of south Brazil. Rev Inst Med Trop Sao Paulo, 52: 69-74.

10. Roldán,W., Cornejo,W. and Espinoza,Y. (2006). Evaluation of the dot enzyme-linked immunosorbent assay in comparison with standard ELISA for the immunodiagnosis of human toxocariasis. Mem Inst Oswaldo Cruz, Rio de Janeiro, 101(1): 71-74.

11. de Savigny, D.H, Voller, A. And Woodruff, A.W. (1979). Toxocariasis: serological diagnosis by enzyme immunoassay. J. Clin. Pathol, 32: 284-288.

12. Magnaval, J.F, Fabre, R., Maurieres, P., Charlet, J.P and de Larrard, B. (1991). Application of the western blotting procedure for the immunodiagnosis of human toxocariasis. Parasitol Res, 77: 697-702.

13. Suharni, M., Norhaida, C.A. and Noordin, R. (2009). Development and Evaluation of a Sensitive and Specific Assay for Diagnosis of Human Toxocariasis by Use of Three Recombinant Antigens (TES-26, TES-30USM, and TES120). J. Clin Microbiol, 47(6): 1712-1717.

14. Chieffi, P.P., Dos Santos, S.V., Queiroz, M.L. and Lescano, S.A. (2009) Human toxocariasis: contribution by Brazilian researchers. Rev Inst Med Trop Sao Paulo 51: 301-308.

15. María, V.B., Gioia, L.M., María, Á.L. and José, M.A. (2012) An evaluation of the dot-Elisa procedure as a diagnostic test in an area with a high prevalence of human Toxocara canis infection. Mem Inst Oswaldo Cruz, Rio de Janeiro, 107(2): 194-197.

16. Maizels, R.M, Schabussova, I., Callister, D.M. and Nicoll, G. (2006) Molecular biology and immunology of Toxocara canis. In: Holland CV, Smith HV (Eds.) Toxocara: The Enigmatic Parasite. Cambridge MA3-17.

17. Peixoto, P. L., Nascimento, E., Cançado, G. G. L., Miranda, R. R. C. and Rocha R. L. (2011) Identification of candidate antigens from adult stages of Toxocara canis for the serodiagnosis of human toxocariasis. Mem Inst Oswaldo Cruz, Rio de Janeiro, 106(2): 200-206.

18. Lowry, O.H., Rosebroug, N.J., Farr, A.L. and Randall, R.J. (1951) Protein measurement with the folin phenol reagent. J. Biol. Chem, 193: 265-275.

19. Laemmli, U. K. (1970) Cleavage of structural protein during the assembly of head of bacteriphage T4. Nature, 277: 680685.

20. Wijffels, G. L. (1994) The secreted cathepsin L-like proteinases of the trematode, Fasciola hepatica, contain 3- hydroxyproline residues. Biochem. J, 299: 781-790.

21. Burnette, W.N. (1981). Western blotting": electrophoretic transfer of proteins from sodium dodecyl sulfatepolyacrylamide gels to unmodified nitrocellulose and radiographic detection with antibody and radioiodinated protein A. Anal Biochem, 112(2):195-203.

22. El-Massry, A. A. (1999) Characterization of antigenic property of Toxocara canis and Toxascaris adults and larvae through immunodiagnosis electrophoresis (SDS-PAGE) and western blot technique. J. Egypt Soc Parasitol, 29: 335-45.

23. Sun,T., Bellosa, M. L., Lucio-Forster, A., Ho, D. S. and Bowman, D. D. (2007) A comparison of the protein constituents of the major body compartments of the dog roundworm, Toxocara canis. Veterinary Parasitology., 150 : 111-115.

24. Nawal, A.H. and Mona, S.M. (2008) Serodiagnosis of Human Toxocariasis Using Adult Antigens of Toxocara canis. Research Journal Parasitology., 3 (3):85-91.

25. Aida, E.A. (1999) Characterization of antigenic property of Toxocara canis and Toxascaris leonina adults and larvae through immunodiagnostic electrophoresis (SDS-PAGE) and Western blot technique. J. Egypt. Soc. Parasitol. 29: 335-345.

26. Watthanakulpanich, D., Smith, H.V., Hobbs, G., Whalley, A.J. and Billington, D. (2008) Application of Toxocara canis excretory-secretory antigens and $\operatorname{IgG}$ subclass antibodies (IgG1-4) in serodiagnostic assays of human toxocariasis. Acta Trop, 106: 90-95. 